\title{
The physiological response of Northern krill (Meganyctiphanes norvegica) to temperature gradients in the Kattegat
}

\author{
Reinhard Saborowski*, Markus Salomon \& Friedrich Buchholz \\ Biologische Anstalt Helgoland-AWI, Meeresstation, Postfach 180, D-27483 Helgoland, Germany \\ E-mail: rsaborowski@awi-bremerhaven.de (*author for correspondence)
}

Key words: Meganyctiphanes norvegica, respiration, temperature, vertical migration, Kattegat

\begin{abstract}
The Alkor-Deep $(140 \mathrm{~m})$, which forms part of a depression system in the northern Kattegat channel east of the island of Læsø (Denmark), is the location of a self sustaining population of Northern krill, Meganyctiphanes norvegica (Euphausiacea). This population is exposed to one of the most pronounced thermal gradients within the distributional range of this pelagic crustacean. During summer, the temperature of the water column ranges between 4 and 6 in the deep to $16^{\circ} \mathrm{C}$ near the surface which results in the krill being exposed to temperature differences of $8-10{ }^{\circ} \mathrm{C}$ during diel vertical migration. Oxygen consumption rates were used to investigate the physiological adaptation of the animal to such gradients in temperature. The rates were found to increase exponentially from 31 $\mu \mathrm{mol} \mathrm{O} 2 \mathrm{~h}^{-1} \mathrm{~g}_{\mathrm{dw}}{ }^{-1}$ at $4{ }^{\circ} \mathrm{C}$ to $72 \mu \mathrm{mol} \mathrm{O}_{2} \mathrm{~h}^{-1} \mathrm{~g}_{\mathrm{dw}}{ }^{-1}$ at $16^{\circ} \mathrm{C}$, giving a $Q_{10}$-value of 2.0 , and indicating that physiological adaptation to varying thermal conditions does not take place. Behavioural adaptations are discussed which may help the krill to cope with large temperature gradients in their environment.
\end{abstract}

\section{Introduction}

Northern krill, Meganyctiphanes norvegica, is an integral component of many zooplankton communities in the north and north-east Atlantic regions. It is abundant in an unusually wide area from the SubArctic to the Mediterranean and is known to perform extensive diurnal vertical migrations (Mauchline \& Fisher, 1969). Towards the Baltic Sea, krill is frequently found in the Skagerrak but is absent south of the Belt Sea and the Øresund. The Kattegat, where the marine waters of the Skagerrak and the brackish waters of the Baltic Sea meet, hosts an apparently self-sustaining krill population within a series of deeps east of the island of Læsø. The krill population of the Alkor-Deep was first described by Boysen \& Buchholz (1984) and Buchholz \& Boysen-Ennen (1988) and thereafter was the subject of several studies on e.g. population dynamics, biochemical composition, nutrition and biochemical adaptation. The diel vertical migration and distribution patterns were investigated by Buchholz et al. (1995) and Tarling et al. (1998). These studies showed that, during the day, krill remained within the basin at depths below $80 \mathrm{~m}$ and often concentrated at the north or south rim. Buchholz et al. (1995) found that krill did not migrate into the uppermost warm surface waters, but penetrated into the discontinuity layer. The authors proposed that the krill were prevented from migrating any higher because they had reached their upper thermal tolerance limit of $14-15{ }^{\circ} \mathrm{C}$. Accordingly, krill were exposed to a maximum temperature difference of about $10{ }^{\circ} \mathrm{C}$ when migrating from the deep cold layers to the subsurface layers where their tolerance limit is met. Given the wide range of temperatures experienced by krill during a typical diurnal vertical migration in this region, this study investigates the capacity of krill to adapt physiologically to these conditions. Respiration rates served as a measure for the overall metabolic performance.

\section{Materials and methods \\ Description of the study site}

The Kattegat is a mostly shallow $(<30 \mathrm{~m})$ transition zone between the North Sea and the Baltic Sea. Five basins more than $100 \mathrm{~m}$ deep (Ulrich, 1983) are found 
in the northern part of the Kattegat, east of the island of Læsø. The Alkor Deep ( $\left.11^{\circ} 25.10 \mathrm{E}, 57^{\circ} 16.55 \mathrm{~N}\right)$, the current study site (Figure 1), is the largest of these basins with a span of $3.5 \mathrm{~km} \times 1 \mathrm{~km}$ and a maximum depth of $140 \mathrm{~m}$.

Hydrographically, the northern Kattegat is characterized by an outflow of brackish surface water from the Baltic Sea northward, and an opposing inflow of deep water from the North Sea. Accordingly, the water column is highly stratified into three main layers, a deep marine layer, an intermediate mixed layer and a brackish surface layer.

The vertical profiles of salinity were similar between summer and winter (Figure 2a) in the deeper part of the water column, where values around 33-34 PSU prevailed. In winter, salinity gradually decreased towards the surface, dropping below 31 PSU at $20 \mathrm{~m}$ and reaching a minimum of 26 PSU in the surface layer. The same gradual decrease was also found in summer, but salinities at the surface were lower than in winter (between 20 and 25 PSU).

The temperature profiles showed pronounced differences between seasons (Figure 2b). The bottom water was always cold between 4 and $6{ }^{\circ} \mathrm{C}$ and these temperatures were recorded throughout the whole water column during the winter situation. In summer, cold waters of $8{ }^{\circ} \mathrm{C}$ were found from the bottom up to $80 \mathrm{~m}$. A slight increase in temperature towards 10 ${ }^{\circ} \mathrm{C}$ appeared between 70 and $50 \mathrm{~m}$. In the mixed layer between $50 \mathrm{~m}$ to $15 \mathrm{~m}$, there was a large temperature shift from $10^{\circ} \mathrm{C}$ to $15^{\circ} \mathrm{C}$ whilst in the surface layers, temperature was once again quite uniform, around 16 ${ }^{\circ} \mathrm{C}$.

\section{Respiration measurements}

Respiration measurements were carried out during a winter and a summer cruise (4-18 March 1997 and 22 July to 5 August 1998, respectively) on board the research vessel FS Heincke. Samples were collected during short night hauls with a multiple opening and closing net and environmental sensing system (MOCNESS, Wiebe, 1985) which was towed at 2.5 knots in the $20-50 \mathrm{~m}$ depth layer. The krill were immediately transferred into large basins (200 l) with aerated water and were allowed to recover for a few hours. Then, individuals were transferred into new aquaria (51) which were adjusted to the experimental temperature of 4,8 , 12 and $16{ }^{\circ} \mathrm{C}$, respectively. In order to minimize the effects of different maturation stages and body size, only males of an average length of $25-30 \mathrm{~mm}$ were se-

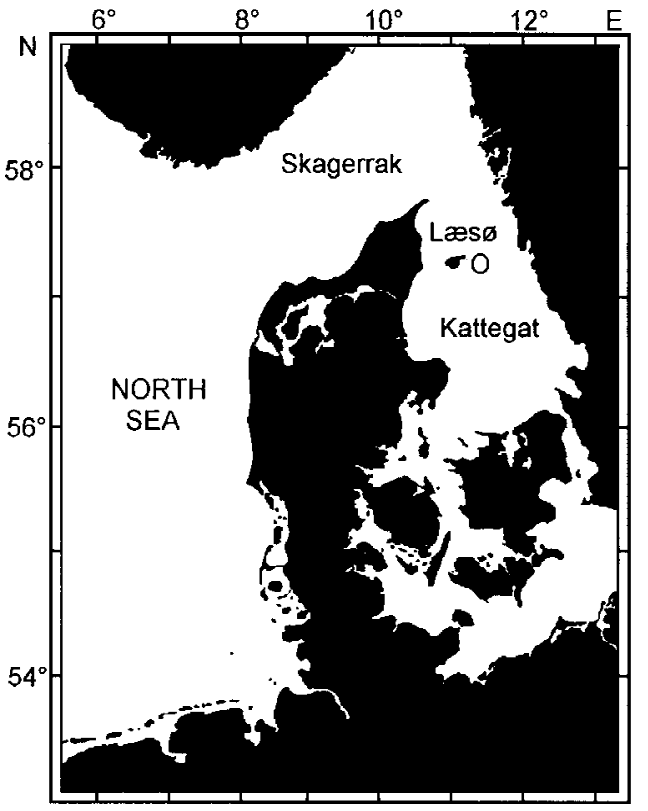

Figure 1. Sampling site east of the island Læs $\varnothing$ in the Kattegat Channel. The position of the Alkor Deep $(140 \mathrm{~m})$ is indicated by the circle.

lected. The respiration measurements were carried out in each of six chambers of 1.641 volume. Five chambers were equipped with 2-5 krill, while one chamber served as a control. Measurements were carried out for several hours in the dark at constant temperature. The chambers were equipped with an internal current system as described in detail by Saborowski \& Buchholz (1998) to encourage natural swimming behaviour. Oxygen consumption rates as measured with Clarketype electrodes (Strathkelvin Instruments, model 928), were normalized to dry weight and expressed as $\mu \mathrm{mol}$ $\mathrm{O}_{2} \mathrm{~h}^{-1} \mathrm{~g}_{\mathrm{dw}}{ }^{-1}$.

The $Q_{10}$-value, which provides a measure of the influence of temperature on metabolic processes, was calculated according to van t'Hoff's law:

$$
Q_{10}=\left(\frac{R_{2}}{R_{1}}\right)^{10 /\left(T_{2}-T_{1}\right)},
$$

where $R_{2}$ and $R_{1}$ are the respiration rates at the temperatures $T_{2}$ and $T_{1}$.

\section{Results and discussion}

The respiration rates were not significantly different between summer and winter, and accordingly, data from both seasons were combined in the following. Oxygen consumption rates were lowest at $4{ }^{\circ} \mathrm{C}$ 


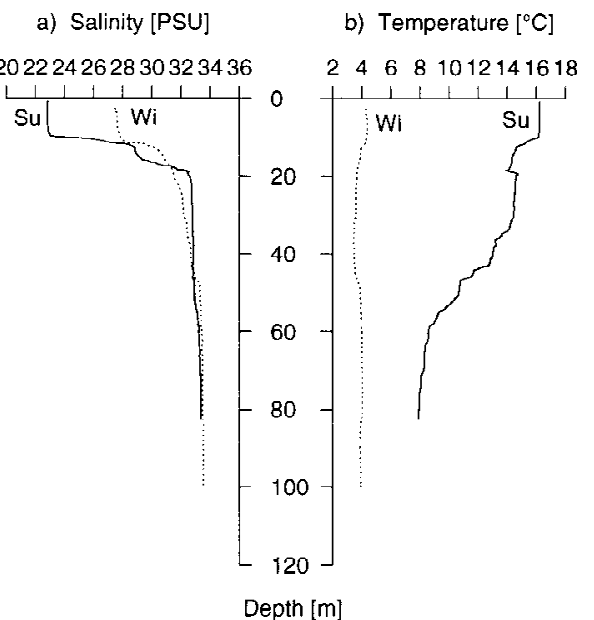

Figure 2. Vertical profiles of (a) salinity and (b) temperature in the Alkor-Deep during winter (early March 1997) and summer (August 1998).

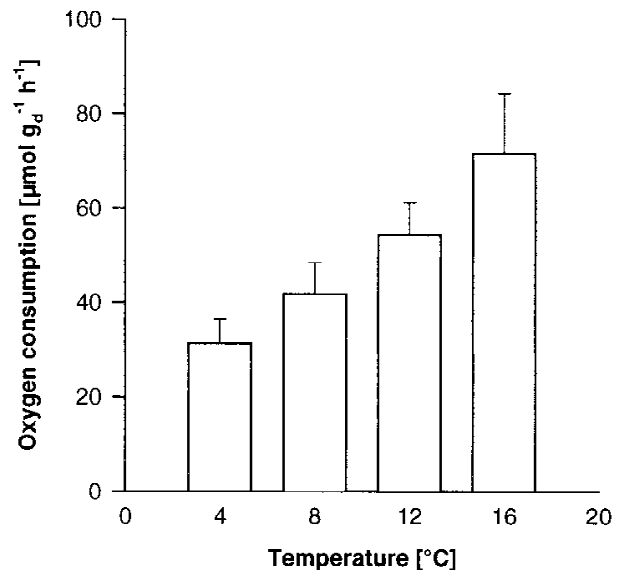

Figure 3. Respiration rates in relation to temperature of male krill. (Means \pm s.d., $n=12-15$ ).

amounting to $31.4 \mu \mathrm{mol} \mathrm{O} \mathrm{h}^{-1} \mathrm{~g}_{\mathrm{dw}}{ }^{-1}$. At $8{ }^{\circ} \mathrm{C}$, respiration increased to $41.8 \mu \mathrm{mol} \mathrm{O} \mathrm{h}^{-1} \mathrm{~g}_{\mathrm{dw}}{ }^{-1}$ and reached $72 \mu \mathrm{mol} \mathrm{O} \mathrm{h}^{-1} \mathrm{gdw}^{-1}$ at $16{ }^{\circ} \mathrm{C}$ (Figure 3). The increase of respiration rates with temperature followed an almost perfect exponential curve $(y=24.06$ $\left.\mathrm{e}^{(0.06817 \cdot x)}, r^{2}=0.9998\right)$. Accordingly, over the short term krill are not able to compensate for temperature effects by adaptive physiological mechanisms. This is also supported by the $Q_{10}$-value which was calculated from the respiration rates obtained over the entire range of experimental temperatures $\left(4{ }^{\circ} \mathrm{C}-16\right.$ $\left.{ }^{\circ} \mathrm{C}\right)$. The resulting $Q_{10}$-value of 2.0 is not exceptionally low as would be suggested in the case of metabolic adaptation. These results are in agreement with previous work by Hirche (1984) on krill from the Swedish

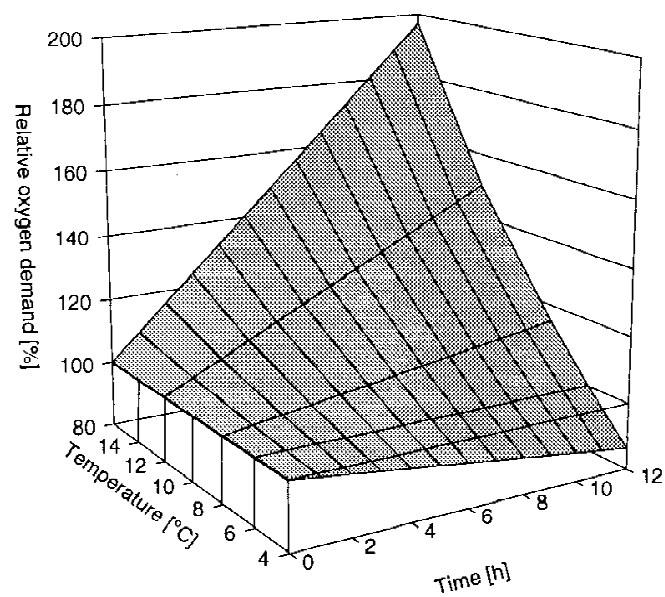

Figure 4. Relative oxygen demand in relation to temperature and duration of exposure. The reference value of $100 \%$ corresponds to averaged deep water temperatures $\left(6^{\circ} \mathrm{C}\right)$.

Gullmarsfjord. Accordingly, krill had to spend more energy on basic metabolic processes in warm, rather than in cold, waters. As the temperature in the Kattegat gradually increases during summer over a comparatively large vertical distance, krill are subjected to a concomitant increase of metabolic costs during the course of their upward migration (Figure 4). On the assumption that $6{ }^{\circ} \mathrm{C}$ is the lowest summer temperature of the deep water, an average sized krill (50 mg dry weight, approx. $30 \mathrm{~mm}$ of length) would consume $1.81 \mu \mathrm{mol}$ oxygen per hour which equals $43.46 \mu \mathrm{mol}$ per day. If this krill moves up and enters water of 12 ${ }^{\circ} \mathrm{C}$ the oxygen consumption would increase to 2.73 $\mu \mathrm{mol}$ per hour and $65.43 \mu$ moles per day. Nevertheless, since krill do not remain in upper water layers during the entire day but only during the night, a more realistic figure would be obtained through assuming they stayed $6 \mathrm{~h}$ up and $18 \mathrm{~h}$ down as observed in the summer, which gives an average value of $51.7 \mu$ moles per day. This would increase the metabolic cost in a krill to $12 \%$ more than if it remained in the deep cool water over the entire $24 \mathrm{~h}$ period, and this does not include the potential extra cost of making a vertical ascent. However, a more significant effect than on the integrated daily energy consumption is given when concerning immediate metabolic changes. In this respect, a variation of temperature from $6{ }^{\circ} \mathrm{C}$ to $12{ }^{\circ} \mathrm{C}$ would increase metabolic rates by $50 \%$ which can be considered to cause stress on any physiological level.

In order to demonstrate a typical distribution pattern of high vertical resolution at day and night, we here extracted data from catches at noon and midnight 


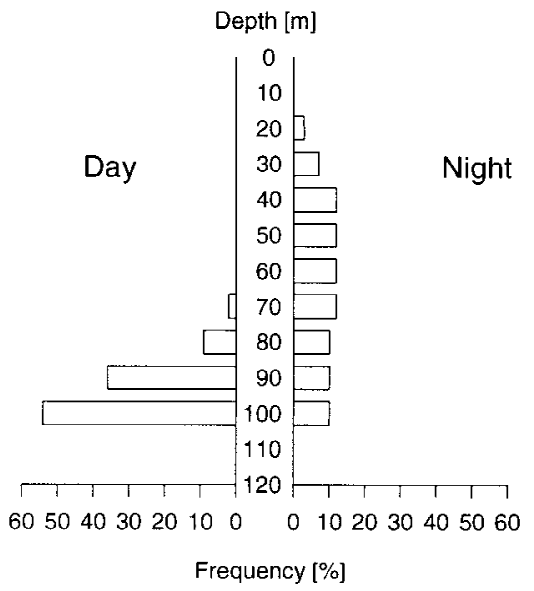

Figure 5. Vertical distribution of krill during day and night (based on data from Buchholz et al., 1995).

obtained in August 1989 (Buchholz et al., 1995) The pattern encountered in 1998 were largely identical. During the day, the entire krill population was found near the bottom layers of the Alkor Deep (Figure 5). Only very few animals were caught above $80 \mathrm{~m}$. More than $80 \%$ of the total catch was obtained from 80 $\mathrm{m}$ and deeper. During the night, krill migrated into the upper water layers but simultaneously dispersed within the water column. While no krill was caught at the surface, numbers increased at 20 and $30 \mathrm{~m}$. A comparatively low but uniform krill density was present from $40 \mathrm{~m}$ to $100 \mathrm{~m}$. This dispersed nocturnal vertical distribution pattern indicates that not the entire krill population uniformly moved towards upper water layers and stayed there for the whole night feeding e.g. on phytoplankton. The time an individual spent in warmer layers appeared to be shorter than potentially possible presuming that this behaviour would be physiologically advantageous. It would result in a reduction of negative thermal effects by variation of duration or frequency of the ascent. Although metabolic extra costs in warmer waters should be covered by additional feeding, potential disadvantages, e.g. imbalances between anabolic and catabolic processes, can be minimized or avoided in this way.

In conclusion, it seems that krill are not able to adapt metabolically to the varying thermal conditions they encounter during the course of diurnal vertical migrations. However, they may compensate thermal effects by their vertical migration behaviour. Detailed fine scale studies on the distribution pattern including a comparison with regions where krill are exposed to isothermic conditions would help to clarify this suggestion.

\section{Acknowledgements}

This study is part of the project "Impact of a climatic gradient on the Physiological Ecology of a Pelagic crustacean" (PEP) of the EU MAST III program, contract no. MAS3-CT95-0013. We are grateful to the PEP-team for help on board.

\section{References}

Boysen, E. \& F. Buchholz, 1984. Meganyctiphanes norvegica in the Kattegat: studies on the annual development of a pelagic population. Mar. Biol. 79: 195-207.

Buchholz, F. \& E. Boysen-Ennen, 1988. Meganyctiphanes norvegica in the Kattegat: studies on the horizontal distribution in relation to hydrography and zooplankton. Ophelia 29: 71-82.

Buchholz, F., C. Buchholz, J. Reppin \& J. Fischer, 1995. Diel vertical migrations of Meganyctiphanes norvegica in the Kattegat: comparison of net catches and measurements with acoustic doppler current profilers. Helgoländer Meeresunters. 49: 849-866.

Hirche, H.-J., 1984. Temperature and metabolism of plankton 1. Respiration of Antarctic zooplankton at different temperatures with a comparison of Antarctic and Nordic krill. Comp. Biochem. Physiol. 77A: 361-368.

Mauchline, J. \& L. R. Fisher, 1969. The Biology of Euphausiids. Adv. Mar Biol. 7: 1-545.

Saborowski, R. \& F. Buchholz, 1998. Internal current generation in respiration chambers. Helgoländer Meeresunters. 52: 103-109.

Tarling, G. A., J. B. L. Matthews, R. Saborowski \& F. Buchholz, 1998. Vertical migratory behaviour of the euphausiid, Meganyctiphanes norvegica, and its dispersion in the Kattegat Channel. Hydrobiologia 375/376 (Dev. Hydrobiol. 132): 331-341.

Ulrich, V. J., 1983. Zur Bathymetrie und Topographie der nördlichen Kattegat-Rinne. Meeresforsch. 30: 61-68.

Wiebe, P. H., A. W. Morton, A. M. Bradley, R. H. Backus, J. E. Craddock, V. Barber, T. J. Cowles \& G. R. Flierl, 1985. New developments in the MOCNESS, an apparatus for sampling zooplankton and micronekton. Mar. Biol. 87: 313-323. 